\title{
Girls and Dolls
}

\author{
Claudia Mitchell and Jacqueline Reid-Walsh
}

$\cos 80$

In this themed issue of GHS, "Interrogating the Meaning of Dolls: New Directions in Doll Studies," guest edited by noted doll researcher Miriam Forman-Brunell, we are introduced to a new generation of doll researchers who continue to explore the connections between girls and dolls. Similar to girls' other types of play such as domestic play with miniature kitchens and with dollhouses, their playing with dolls is far from being an uncontested area of study within feminist scholarship. In the eighteenth century Jean Jacques Rousseau, and Maria and Richard Edgeworth elaborated the function of the fashion doll as a way of preparing girls for their future life. Dolls became more of a problematic topic in the twentieth century when much of the discussion centered around Barbie. In an article we wrote on Barbie some years ago (ReidWalsh and Mitchell 2000), for example, we played with the expression "just a doll" (175) arguing that, on the one hand, Barbie's low cultural status as a doll called into question the vast amount of controversy generated by one piece of molded plastic, and, on the other, trivialized girls' play objects.

The possibilities of engaging in doll study have continued to expand, and of course the types of dolls that can be analyzed have also expanded to include contemporary fashion dolls such as Barbie and Bratz, and the American Girl Doll along with Regency paper dolls, Raggedy Ann dolls, and homemade or DIY (do-it-yourself) dolls. This work on the study of dolls also includes doll-related artefacts such as Barbie Dream Houses. In this issue of GHS, contributors continue the exploration of dolls and the significance in the lives of girls of playing with dolls as well as making them. At the same time they point in their work to new directions in the study of material culture in Girlhood Studies. 


\section{References}

Edgeworth, Marie, and Richard Edgeworth. [1798]1974. Practical Education, 2 vols. ed. G. Luria. New York: Garland.

Reid-Walsh, Jacqueline, and Claudia Mitchell. 2000. "Just a doll'? 'Liberating' accounts of Barbie-play." Review of Education/Pedagogy/Cultural Studies 22, no. 2: $175-190$.

Rousseau, Jean Jacques. [1762]1979. Emile; or, on Education, Trans. and ed. Harold Bloom. New York: Basic Books. 